\title{
Acute myocardial infarction risk factors and correlation of its markers with serum lipids
}

\begin{abstract}
Myocardial infarction is a term applied to myocardial necrosis secondary to an acute interruption of the coronary blood supply. Atherosclerosis is by far the most common cause of myocardial infarction. According to the INTERHEART study report, nine factors are responsible for $90 \%$ of myocardial infarctions. Modifiable risk factors include Diabetes mellitus, smoking, hypertension, hyperlipidemia, sedentary life style, obesity, stress and depression. The combination of several risk factors further enhances the risk. This study aimed to evaluate the frequency of risk factors among AMI patients in Tajoura National Heart Center, Libya, and to detect the presence of correlation between AMI markers and serum lipids. This study was conducted from September, 2007 to April, 2008. On 120 acute myocardial infarction patients, 86 males and 34 females, and the results were compared to the results of 40 healthy persons ( 20 male and 20 female) with matched ages with the patients. The results of this study concluded that, ages of most male patients were from 45-65 years old, but most of female ages from 55-75 years old which means that, the incidence of AMI was occurred in males earlier than females. The most prevalent risk factor in male and female patients is diabetes. Smoking is the second risk factor in males, and hypertriglyceridemia was the second risk factor among female patients. The study was also showed correlation between total CK and CK-MB and total cholesterol concentration, but this was not found between LDH, TN-t and cholesterol, on the other hand, LDH was correlated with HDLC.
\end{abstract}

Keywords: risk factors, lipids, HDLC, hyperlipidemia, LDH, CK-MB
Volume 3 Issue 4 - 2017

\author{
Azab Elsayed Azab,' Ata Sedik Ibrahim \\ Elsayed $^{2}$ \\ 'Department of Zoology,Alejelat, Zawia University, Libya \\ 2Department of Biomedical Sciences, Dar Al Uloom University, \\ Saudi Arabia
}

Correspondence: Azab Elsayed Azab, Department of Zoology, Faculty of Science, Alejelat, Zawia University, Libya, Email azabelsaied@yahoo.com

Received: May 30, 2017 | Published: July 14, 2017
Abbreviations: AMI, acute myocardial infarction; MI, myocardial infarction; CK, creatine kinase; ALT, aspartate aminotransferase; CVD, cardiovascular diseases; AIP, atherogenic index of plasma; CRI-I, castelli's risk index; AC, atherogenic coefficient

\section{Introduction}

Myocardial Infarction (MI) is a term which is used for defining the necrosis in the heart muscle due to the lack of the oxygen need of myocardium which cannot be supplied by the coronaries. It is characterized by chest pains or discomfort which may travel into the shoulder, arm, back, neck or jaw. ${ }^{1,2}$ Acute myocardial infarction (AMI) is considered more appropriately part of a spectrum referred to as acute coronary syndromes, which also includes unstable angina and non-ST-elevation. Patients with ischemic discomfort may or may not have ST-segment elevation. Most of those with ST-segment elevation will develop Q waves. Those without ST elevations will ultimately be diagnosed with unstable angina based on the presence of cardiac enzymes. Approximately $90 \%$ of myocardial infarction results from an acute thrombus that obstructs an atherosclerotic coronary artery. The highest risk of fatality occurs within the initial hours of onset of AMI. Thus, early diagnosis of cardiac ischemia is critical for the effective management of patients with AMI. Improper diagnosis of patients with chest pain often leads to inappropriate admission of patients without AMI and vice versa. In addition to clinical history, physical examination, accurate electrocardiogram findings and assessment of cardiac biomarkers have an important role in the early diagnosis of acute ischemia. The analysis of cardiac biomarkers has become the frontline diagnostic tools for AMI, and has greatly enabled the clinicians in the rapid diagnosis and prompt treatment planning, thereby reducing the mortality rate to a great extent. ${ }^{4}$ There are some cardiac markers that can be used in the diagnosis of myocardial infarction among them include, aspartate transaminase, alanine transaminase, troponin I, creatine kinase, etc. Creatine kinase (isoenzymes CK-MB) is the enzyme used as a definitive serum marker for the diagnosis or exclusion of acute myocardial infarction., ${ }^{2,5}$ Lactate dehydrogenase, creatine kinase and their isoenzymes exhibited better cardiac specificity. After the discovery that cardiac troponins I and $\mathrm{T}$ have the desired specificity, they have replaced the cytosolic enzymes in the role of diagnosing myocardial ischemia and infarction. The use of the troponins provided new knowledge that led to revision and redefinition of ischemic myocardial injury as well as the introduction of biochemicals for estimation of the probability of future ischemic myocardial events. These markers, known as cardiac risk markers, evolved from the diagnostic markers such as CK-MB or troponins, but markers of inflammation also belong to these groups of diagnostic chemicals. ${ }^{6}$ The markers that are well suited for the early diagnosis of AMI within the time interval 0-6 hours after symptom onset are myoglobin, H-FABP and CK-MB isoforms. CK-MB mass measurement is suitable in the 6-24 hours interval; CK-MB based on activity measurement is more sensitive in the 12-24 hours interval, and the other cardiac markers like total CK, cTnT, and cTnI are most reliable after 12 hours from symptom onset. The prolonged diagnostic window of cardiac troponins of several days that is highly sensitive and specific obviates the needs for less specific markers with long diagnostic window like aspartate aminotransferase (ALT) and CK. Based on the recent recommendations by the ESC/ACC, cTnI and $\mathrm{cTnT}$ are the best markers for the confirmation of AMI. CK-MB is the second best marker in the absence of troponins assays. 
Some disease factors contribute to the risk of myocardial infarction and they include diabetes mellitus (type 1 or 2), high blood pressure, dyslipidemia/hypercholesterolemia, particularly high amount of lowdensity lipoprotein, low amount of high density lipoprotein, high triglycerides, and obesity. ${ }^{2,8}$ Atherosclerosis is by far the most common cause of myocardial infarction. According to the INTERHEART study report, nine factors are responsible for $90 \%$ of myocardial infarctions. Modifiable risk factors include Diabetes mellitus, smoking, hypertension, hyperlipidemia, sedentary life style, obesity, stress and depression. The combination of several risk factors further enhances the risk. Treatment of hypertension and dyslipidemia causes reduction in risk of myocardial infarction. As there is variability in the prevalence of risk factors in different populations, a highly potent factor in one country could be less important in another one. ${ }^{9}$ According to the study from west Sweden, acute myocardial infarction (AMI) among women is commonly affected by multiple risk factors. Hence, women more commonly have diabetes and arterial hypertension, while cigarette smoking is the only factor of lower frequency. On the other side, men have 3-6 times higher risk of developing disease compared to women, since women develop disease approximately ten years later. The risk of developing diseases is increased with aging. ${ }^{10}$ Diabetes increases the risk of cardiovascular diseases (CVD) and mortality by about four times in women and about two folds in men, $30 \%$ of patients with an episode of myocardial infarction had type II Diabetes mellitus. ${ }^{9}$

Smoking 1-5 cigarettes daily increases the risk for developing AMI by $38.4 \%$, contributing to the fact that the risk for CVD is proportional to the number of cigarettes consumed. Both men and women are equally affected by the harmful effect of smoking (either active or passive); although the effect is probably stronger in women since it affects their natural hormonal protection at a younger age. Smoking has a synergistic effect with other risk factors and it also impacts an increase in CVD when combined with hypertension and diabetes. Studies have shown that, among randomly chosen patients with ACS, smokers, when compared to non-smokers, are twice as likely to have STEMI, indicating a prothrombotic effect of smoking. ${ }^{11}$ Increasing level of smoking increases the risk of AMI. Smoking is on the rise in many low and middle income countries, especially among young people and women. ${ }^{12}$ Hypertension is an equally important risk factor in both genders and its frequency increases with age. The likelihood of developing changes on the CV system depends on the blood pressure values and the length of hypertension. The blood pressure values greater than $110 / 75 \mathrm{mmHg}$ increase the risk for development of CVD in any age group. ${ }^{10}$ This study aimed to evaluate the frequency of risk factors among AMI patients in Tajoura National Heart Center, Libya, and to detect the presence of correlation between AMI markers and serum lipids.

\section{Materials and methods}

This study was conducted in National Cardiology Centre in Tajoura, Libya, from September, 2007 to April, 2008. On 120 AMI patients, 86 males and 34 females, and the results were compared to the results of 40 healthy persons (20 male and 20 female) with matched ages with the patients. The only inclusion criterion was the diagnosis of acute myocardial infarction. Diagnostic criteria are:

i. Cardiac biomarkers had a rise (to at least one time of the upper normal value) or fall after rise (to at least one time of the upper normal value).

ii. At least one of the following characteristics presented: The patient had clinical symptoms of myocardial ischemia, ECG showed new ST segment change or left bundle-branch block, ECG showed pathological Q wave and/or Imaging evidence showed new loss of myocardial activity or regional wall motion abnormality.

The risk factors were identified as follow: the smoking persons who is smoking at least 100 cigarettes in their life time and who, at the time of admission, smoked either every day or some days. Hypertension, means that the systolic blood pressure $\geq 140 \mathrm{~mm} \mathrm{Hg}$ and the diastolic blood pressure $\geq 90 \mathrm{~mm} \mathrm{Hg}$. Diabetes was considered if the fasting Blood sugar $\geq 110 \mathrm{mg} / \mathrm{dL}$. Hypercholesterolemia and Hypertriglyceridemia (Dyslipidemia) were labeled as total Cholesterol $\geq 200 \mathrm{mg} / \mathrm{dl}$ and Triglycerides greater than $150 \mathrm{mg} / \mathrm{dl}$, respectively. The data were extracted from the patients' medical history and discharge letters, as well as from their electronic and paper records. VLDL-cholesterol was estimated by using the Friedewald equation. The atherogenic ratios were calculated as follows:
i. Castelli's risk index (CRI-I) $=\mathrm{TC} / \mathrm{HDLc}$
ii. Atherogenic coefficient $(\mathrm{AC})=(\mathrm{TC}-\mathrm{HDLc}) / \mathrm{HDLc}$ and
iii. Atherogenic index of plasma (AIP) $=\log$ TG/HDLc

\section{Statistical analysis}

Data of patients and control groups were entered in electronic form using Microsoft Excel 2010. The data were analyzed and presented using descriptive statistics (absolute and relative numbers, measures of means and standard deviation) and appropriate statistical tests ( $\chi^{2 /}$ test, Mann-Whitney U test, Fisher test, correlation, and frequency tests), Kolmogorov-Smirnova and Shapiro-Wilk tests were used to see that data is following normal distribution or not. Those parameters which were not following normal distribution were analyzed by nonparametric tests using Graphpad prism analytical software. A probability level or $\mathrm{p}$ value less than $0.05(\mathrm{P}<0.05)$ was considered statistically significant.

\section{Results}

This study was conducted on 120 AMI patients and 40 healthy persons, the ages of patients were illustrated in Figure 1. We noticed that the ages of most mal patients were from $45-65$ years old (52\% of male patients), but most of female ages from $55-75$ years old ( $70 \%$ of female patients), which means that, the incidence of AMI was occurred in males earlier than females. The data illustrated in Figure 2 , showed the prevalence of risk factors among male and female patients, from this figure we noticed that, the most prevalent risk factor in male and female patients is diabetes, $70.9 \%$ and 72.7 for males and females respectively. Smoking is the second risk factor in males $(51.2 \%)$, but all of female patients were nonsmoking, on the other hand, hypertriglyceridemia was the second risk factor among female patients. By chi square test we found a highly significant difference between males and females in smoking but there was no significant difference in hypertriglyceridemia (Table 1), the percentages of hypertriglyceridemia were $33.9 \%$ and $40 \%$ for males and females respectively. Prevalence of hypertension among male patients was more than in female, the percentages were $41.2 \%$ for males and $30.3 \%$ for female, this means that the second the third risk factor in males was hypertension. Hypertriglyceridemia was the fourth risk factor among males and females patients with $21.3 \%$ and $30.7 \%$ respectively (Table 1). 


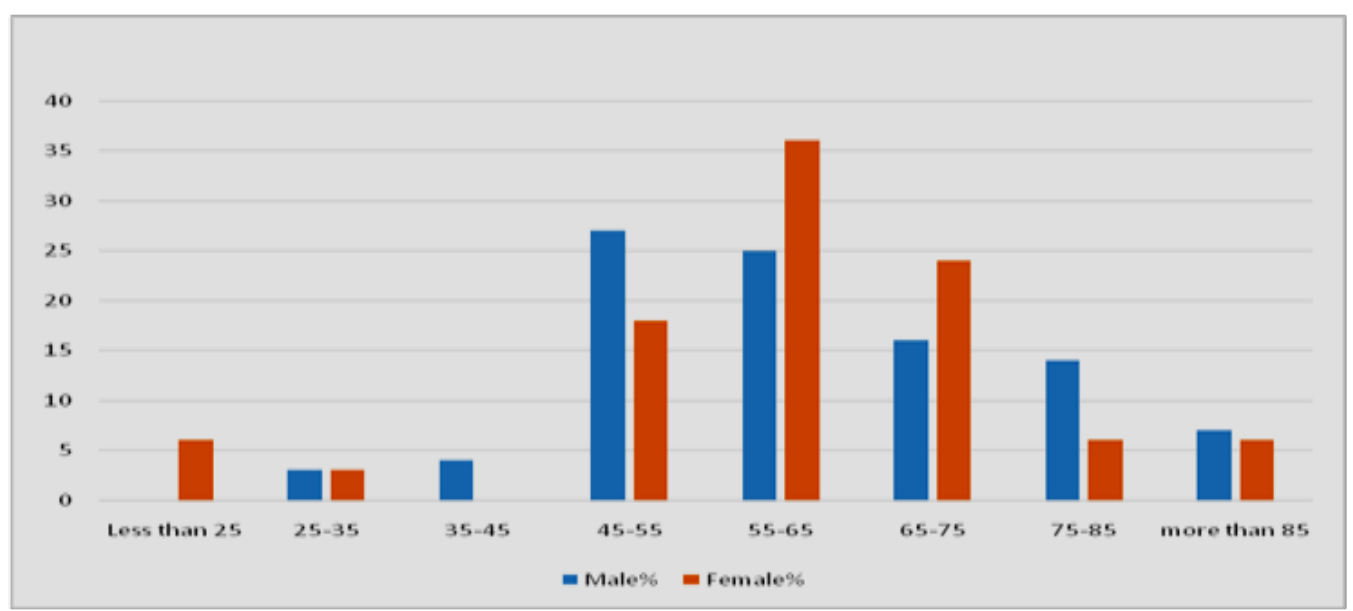

Figure I Distribution of patients according to age and gender.

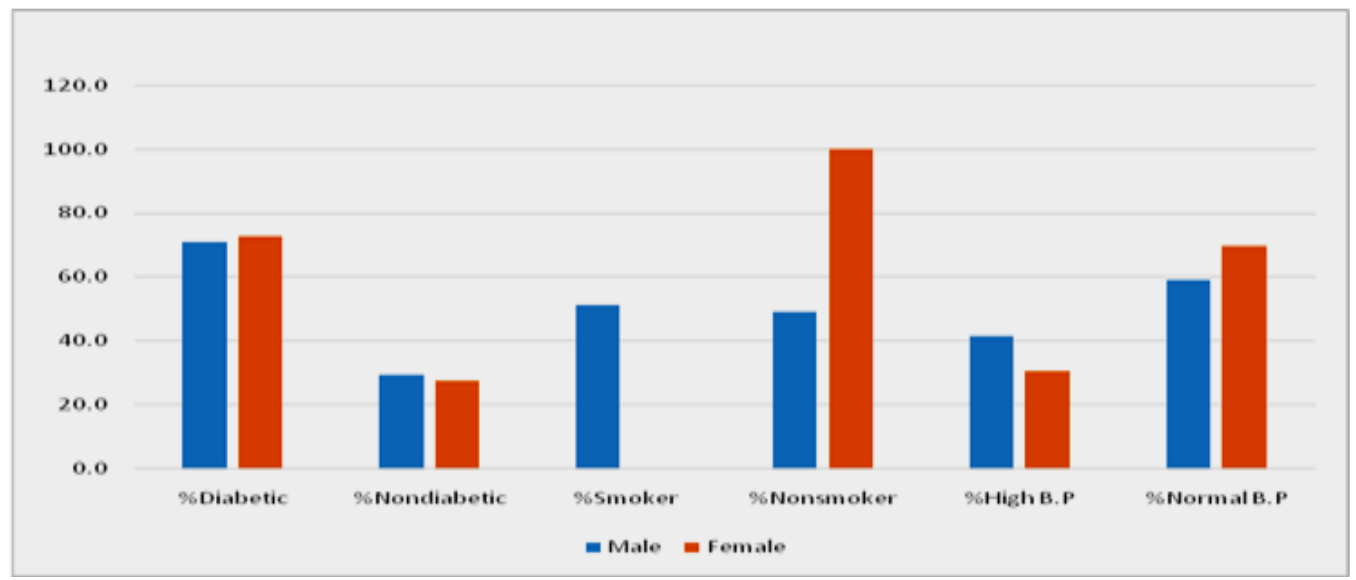

Figure 2 Representation of risk factors among AMI patients.

The illustrated data in Table 2 showed that, cholesterol in female patients was significantly higher than healthy female by $17.8 \%$ $(p<0.05)$, but this was not the case in males. Triglycerides were showed highly significant differences between male and female patients and healthy control persons by $31.9 \%$ and $38.5 \%$ respectively. HDL and LDL were changed significantly in both gender of patients than healthy controls by $-24 \%$ and $-37 \%$ for HDL and $45 \%$ and $13.8 \%$ for LDL in males and females respectively. The results in Table 2 showed dramatic increase in VLDL in both males and females by $39.3 \%$ and $64.9 \%$, this increases were also observed in the calculated CRI, AC, and AIP by $47.7 \%$ and 62.2 for CRI, $86 \%$ and $82.4 \%$ for $\mathrm{AC}$ and $156.6 \%$ and $125.4 \%$ for AIP among male and female patients respectively on comparing with healthy volunteers. Blood sugar concentrations were showed highly significant differences $(\mathrm{p}<0.01)$ on using Mann-Whitney $U$ test, these differences were $83.45 \%$ for males and $108.3 \%$ for females. The data in Table 3 showed the results of correlation test between age and serum lipid, but we not found any significant correlation between age and any of serum lipid, on the other hand, the data of Table 4 which analyzed the correlations between AMI markers as, total CK, CK-MB, LDH and TN-t. The tests showed significant positive correlation between total CK and CK-MB and total cholesterol concentration, but this was not found between LDH, TN-t and cholesterol, on the other hand, LDH was correlated with HDLC. The other lipids as LDL and VLDL had not any significant correlation between AMI markers and them.
Table I Distribution of risk factors according to gender

\begin{tabular}{|c|c|c|c|c|}
\hline Risk factor & & Male \% & Female \% & $\mathbf{p}$ \\
\hline \multirow{3}{*}{ Hypertension } & Yes & 41.2 & 30.3 & \multirow{3}{*}{0.381} \\
\hline & & & & \\
\hline & No & 58.8 & 69.7 & \\
\hline \multirow{3}{*}{ Diabetes } & Yes & 70.9 & 72.7 & \multirow{3}{*}{ I } \\
\hline & & & & \\
\hline & No & 29.1 & 27.3 & \\
\hline \multirow{3}{*}{ Hypercholesterolemia } & Yes & 21.3 & 30.7 & \multirow{3}{*}{0.414} \\
\hline & & & & \\
\hline & No & 78.7 & 69.3 & \\
\hline \multirow{3}{*}{ Hypertriglyceridemia } & Yes & 33.9 & 40 & \multirow{3}{*}{0.625} \\
\hline & & & & \\
\hline & No & 66.1 & 60 & \\
\hline \multirow{3}{*}{ Smoking } & Yes & 51.2 & 0 & \multirow{3}{*}{0} \\
\hline & & & & \\
\hline & No & 48.8 & 100 & \\
\hline
\end{tabular}


Table 2 Serum lipids and sugar of healthy persons and AMI patients

\begin{tabular}{|c|c|c|c|c|c|c|c|c|c|}
\hline & $\begin{array}{l}\text { Cholesterol } \\
\text { Mean士 SD }\end{array}$ & $\begin{array}{l}\text { Triglycerides } \\
\text { Mean士 SD }\end{array}$ & $\begin{array}{l}\text { HDL } \\
\text { Mean } \pm \\
\text { SD }\end{array}$ & $\begin{array}{l}\text { LDL } \\
\text { Mean } \pm \\
\text { SD }\end{array}$ & $\begin{array}{l}\text { VLDL } \\
\text { Mean } \pm \\
\text { SD }\end{array}$ & $\begin{array}{l}\text { CRI } \\
\text { Mean } \pm \\
\text { SD }\end{array}$ & $\begin{array}{l}\text { AC } \\
\text { Mean } \pm \\
\text { SD }\end{array}$ & $\begin{array}{l}\text { AIP } \\
\text { Meant } \\
\text { SD }\end{array}$ & $\begin{array}{l}\text { Blood sugar } \\
\text { Mean } \pm \text { SD }\end{array}$ \\
\hline $\begin{array}{l}\text { Male } \\
\text { Control }\end{array}$ & $155 \pm 12.5$ & $97.8 \pm 15.4$ & $\begin{array}{l}61.1 \pm \\
10.1\end{array}$ & $80 \pm 12.9$ & $\begin{array}{l}19.6 \pm \\
3.07\end{array}$ & $\begin{array}{l}2.62 \pm \\
0.81\end{array}$ & $\begin{array}{l}1.62 \pm \\
0.81\end{array}$ & $\begin{array}{l}0.205 \pm \\
0.08\end{array}$ & $94.3 \pm 10.5$ \\
\hline $\begin{array}{l}\text { Male } \\
\text { Patients }\end{array}$ & $165 \pm 23.2$ & $129 \pm 30.6 *$ & $\begin{array}{l}46.1 \pm \\
28.5^{* *}\end{array}$ & $\begin{array}{l}116 \pm \\
42.8 * *\end{array}$ & $\begin{array}{l}27.3 \pm \\
6.9 * *\end{array}$ & $\begin{array}{l}3.87 \pm \\
1.54^{* *}\end{array}$ & $\begin{array}{l}3.01 \pm \\
1.38^{* *}\end{array}$ & $\begin{array}{l}0.526 \pm \\
0.18 * *\end{array}$ & $173 \pm 45.8^{* * *}$ \\
\hline $\begin{array}{l}\% \\
\text { difference }\end{array}$ & 6.45 & 31.9 & -24.55 & 45 & 39.3 & 47.7 & 86 & 156.6 & 83.45 \\
\hline $\begin{array}{l}\text { Female } \\
\text { Control }\end{array}$ & $146 \pm 20.6$ & $109 \pm 23.7$ & $\begin{array}{l}60.4 \pm \\
12.6\end{array}$ & $\begin{array}{l}82.6 \pm \\
10.5\end{array}$ & $\begin{array}{l}19.4 \pm \\
2.6\end{array}$ & $\begin{array}{l}2.65 \pm \\
0.83\end{array}$ & $\begin{array}{l}1.65 \pm \\
0.83\end{array}$ & $\begin{array}{l}0.256 \pm \\
0.11\end{array}$ & $91.2 \pm 11.5$ \\
\hline $\begin{array}{l}\text { Female } \\
\text { Patients }\end{array}$ & $172 \pm 22.2^{*}$ & $|5| \pm 39.8^{*}$ & $\begin{array}{l}38.0 \pm \\
13.4^{* *}\end{array}$ & $\begin{array}{l}94 \pm \\
25.7^{*}\end{array}$ & $\begin{array}{l}32 \pm \\
7.5 * *\end{array}$ & $\begin{array}{l}4.3 \pm \\
1.23 * *\end{array}$ & $\begin{array}{l}3.3 \pm \\
1.24 * *\end{array}$ & $\begin{array}{l}0.577 \pm \\
0.19 * *\end{array}$ & $190 \pm 55.8^{* *}$ \\
\hline $\begin{array}{l}\% \\
\text { difference }\end{array}$ & 17.8 & 38.5 & -37.1 & 13.8 & 64.9 & 62.2 & 82.4 & 125.4 & 108.3 \\
\hline
\end{tabular}

Table 3 Correlation between age and serum lipids in AMI patients

\begin{tabular}{llllll}
\hline Correlation of age with serum lipids & Cholesterol & Triglycerides & HDL & LDL & VLDL \\
\cline { 2 - 6 } Spearman $r$ & -0.0682 & -0.0717 & -0.13 I & 0.135 & -0.0717 \\
95\% confidence interval & -0.286 to 0.156 & -0.286 to 0.150 & -0.416 to 0.178 & -0.185 to 0.429 & -0.286 to 0.150 \\
P value (two-tailed) & 0.5399 & 0.5142 & 0.3922 & 0.393 I & 0.5142 \\
P value summary & ns & ns & ns & ns & ns \\
\hline
\end{tabular}

Table 4 Correlation between markers of AMI and serum lipids

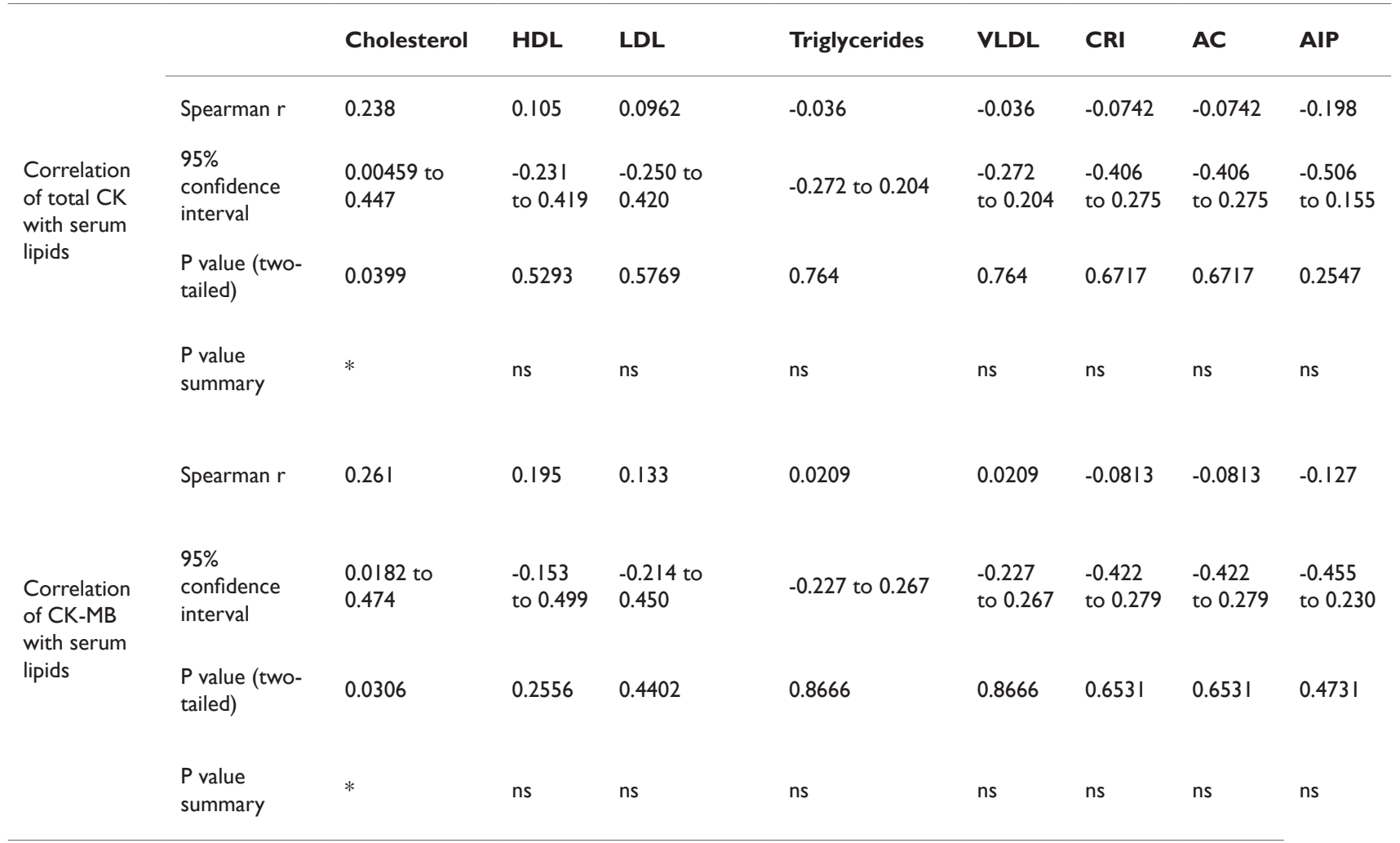


Table Continued..

\begin{tabular}{|c|c|c|c|c|c|c|c|c|c|}
\hline & Cholesterol & HDL & LDL & Triglycerides & VLDL & CRI & $A C$ & AIP & \\
\hline \multirow{4}{*}{$\begin{array}{l}\text { Correlation } \\
\text { of LDH with } \\
\text { serum lipids }\end{array}$} & Spearman $r$ & 0.0973 & 0.447 & 0.0756 & 0.0596 & 0.0596 & -0.44 & -0.44 & -0.317 \\
\hline & $\begin{array}{l}95 \% \\
\text { confidence } \\
\text { interval }\end{array}$ & $\begin{array}{l}-0.150 \text { to } \\
0.333\end{array}$ & $\begin{array}{l}0.0843 \\
\text { to } 0.705\end{array}$ & $\begin{array}{l}-0.310 \text { to } \\
0.440\end{array}$ & -0.192 to 0.304 & $\begin{array}{l}-0.192 \\
\text { to } 0.304\end{array}$ & $\begin{array}{l}-0.709 \\
\text { to } \\
-0.0604\end{array}$ & $\begin{array}{l}-0.709 \\
\text { to } \\
-0.0604\end{array}$ & $\begin{array}{l}-0.629 \\
\text { to } \\
0.0837\end{array}$ \\
\hline & $\begin{array}{l}\mathrm{P} \text { value (two- } \\
\text { tailed) }\end{array}$ & 0.4265 & 0.0152 & 0.6965 & 0.6344 & 0.6344 & 0.0216 & 0.0216 & 0.1073 \\
\hline & $\begin{array}{l}P \text { value } \\
\text { summary }\end{array}$ & ns & $*$ & ns & ns & ns & $*$ & $*$ & ns \\
\hline \multirow{4}{*}{$\begin{array}{l}\text { Correlation } \\
\text { of } T N \text { - } t \text { with } \\
\text { serum lipids }\end{array}$} & Spearman $r$ & -0.225 & -0.206 & 0.274 & -0.145 & -0.145 & 0.188 & 0.188 & 0.149 \\
\hline & $\begin{array}{l}95 \% \\
\text { confidence } \\
\text { interval }\end{array}$ & $\begin{array}{l}-0.512 \text { to } \\
0.107\end{array}$ & $\begin{array}{l}-0.634 \\
\text { to } 0.319\end{array}$ & $\begin{array}{l}-0.236 \text { to } \\
0.665\end{array}$ & -0.452 to 0.193 & $\begin{array}{l}-0.452 \\
\text { to } 0.193\end{array}$ & $\begin{array}{l}-0.353 \\
\text { to } 0.635\end{array}$ & $\begin{array}{l}-0.353 \\
\text { to } 0.635\end{array}$ & $\begin{array}{l}-0.389 \\
\text { to } 0.610\end{array}$ \\
\hline & $\begin{array}{l}\text { P value (two- } \\
\text { tailed) }\end{array}$ & 0.169 & 0.4273 & 0.2719 & 0.3853 & 0.3853 & 0.4848 & 0.4848 & 0.5827 \\
\hline & $\begin{array}{l}\text { P value } \\
\text { summary }\end{array}$ & ns & ns & ns & ns & ns & ns & ns & ns \\
\hline
\end{tabular}

\section{Discussion}

The definition of myocardial infarction is a myocardial cell death due to prolonged ischemia, this death of myocardial cell does not occur immediately after of myocardial ischemia, but occurs after more than six hours. The most common cause of myocardial infarction is atherosclerosis. The risk factors of atherosclerosis are smoking, hypertension, hyperlipidemia, diabetes, gender and age. The present study focused on the effect of gender, age, hypertension, diabetes, and dyslipidemia as a major risk factor among AMI patients in Libya. The present data showed high frequency of AMI in ages from 45 to 65 years old among female, on the other hand the highest frequency of ages among female patients were 55 to 75 years old, this means that acute myocardial infarction is more common in males who are affected at a relatively younger age compared to females. Also, the epidemiological distributions of AMI were different from region to other all over the world; coronary artery disease affects South Asians at a relatively younger age as compared to western population. The study of Rafaqat et al. ${ }^{9}$ included 224 cases of acute myocardial infarction, of these, $69.2 \%$ were males and $30.8 \%$ were females, which matched our results. Also, our results match those of Abbas et al. ${ }^{13}$ and Ahmed et al. ${ }^{14}$ who showed that $73.8 \%$ of AMI patients were male. Ahmed et al. ${ }^{14}$ also found that majority $(87 \%)$ of AMI of patients were male. Male patients were also a dominant entity (85\%) in another study conducted in USA and Canada. ${ }^{15}$

Diabetes was the most predominant risk factor among male and female patients, $70.9 \%$ for males and $72.7 \%$ for females were diabetic. In a hospital based case control study, conducted in a rural population of India, cases of AMI were twice as likely to have history of diabetes compared to controls. ${ }^{16}$ Our study was also in accordance with the results of Rafaqat et al., ${ }^{9}$ which concluded that diabetes mellitus is significantly more common in females. Diabetes is a major independent predictor of morbidity and mortality in acute MI. ${ }^{17,18}$ Smoking was the second risk factor among male patient $(51.2 \%)$, but all the female patients sample were not smoker, this because, the smoking is not an habit among females in most of Arabian and Islamic countries. Smoking appeared to be the second most common risk of AMI. In our study, smoking was significantly $(\mathrm{p}=0.00)$ more common in male patients $(52.2 \%)$ than females $(0 \%)$. This in accordance with the results of Rafaqat et al. ${ }^{9}$ who noted that $52 \%$ of AMI patients were smoker. Also, Jafary et al. ${ }^{19}$ were recorded similar results. A study, conducted in Punjab institute of cardiology, showed that smoking was the most prevalent $(63.4 \%)$ risk factor in young coronary artery disease patients. ${ }^{20}$ Abduelkarem et al. ${ }^{18}$ reported that smoking was an important risk factor among Libyan male acute myocardial infarction patients.

According to the study of Redfors et al., ${ }^{21}$ acute myocardial infarction among women is commonly affected by multiple risk factors. Hence, women more commonly have diabetes and arterial hypertension, while cigarette smoking is the only factor of lower frequency. This which in accordance with our study where $72.2 \%$ of female patients were diabetic and $30 \%$ of them were hypertension. On the other hand, men have 3-6 times higher risk of developing disease compared to women, since women develop disease approximately ten years later. The risk of developing diseases is increased with aging. Endothelial dysfunction and inflammation have a major role in the initiation of the atherosclerotic plaque formation. Atherosclerosis is characterized by lipid accumulation in the vessel walls leading to the formation of an atherosclerotic plaque consisting of a central lipid core surrounded by foamy macrophages and smooth muscle cells covered 
by a fibrous cap. Rupture of the fibrous cap leads to communication between the lipid content of the plaque and the blood flowing through the arterial lumen. The tissue factor expressed by the macrophages activates the platelets eventually leading to the formation of intraluminal thrombus. Finally occlusion of the coronary artery by the thrombus reduces the blood supply to the myocardial tissues leading to ischemia and necrosis, eventually causing myocardial infarction. ${ }^{4}$

Hypertriglyceridemia was the second risk factor among female patients in the present study after diabetes, but it was the fourth risk factor among males. The role of triglycerides as an independent risk factor for cardiovascular disease has been debated during a long time. High triglyceride levels are a significant independent predictor of coronary heart disease and ischemic stroke. Based on the study of Domma et al. ${ }^{3}$ by using a Cox regression model, indicated that the incidence of myocardial infarction and mortality increased with increasing serum triglyceride values, which in accordance of our study as illustrated in Table $1 \& 2$, that the prevalence of hypertriglyceridemia among AMI patients were $30.7 \%$ and $21.3 \%$ with percentage of differences from control $38.5 \%$ and $31.9 \%$ for females and males respectively. Recent genetic studies and randomized trials demonstrated that hypertriglyceridemia may be a cause of cardiovascular disease. ${ }^{22,23}$ The interaction between LDL cholesterol and HDL-cholesterol indicated that risk is 11.6-fold higher for men with LDL cholesterol levels above $160 \mathrm{mg} / \mathrm{dl}$ and HDL-cholesterol levels below $35 \mathrm{mg} / \mathrm{dl}$ as compared to men with LDL cholesterol levels below $100 \mathrm{mg} / \mathrm{dl}$ and HDL-cholesterol levels above $45 \mathrm{mg} / \mathrm{dl} .^{24}$ In the present study, the mean HDL was $46 \mathrm{mg} / \mathrm{dl}$ and $38 \mathrm{mg} / \mathrm{dl}$ for male and female patients respectively with percentage of differences between patients and control $-24 \%$ and $-37 \%$. In the same time the LDL levels were elevate by $45 \%$ and $13.8 \%$ in males and females respectively, which means that the risk of lowering HDL and high LDL was more common in males more than females. The relationship between HDL cholesterol and coronary heart disease is complex and comprises at least three independent issues. First, a low level of circulating LDL is a surrogate marker for an atherogenic metabolic situation commonly known as the metabolic syndrome, which also comprises the components obesity, hypertension, insulin resistance, and hypertriglyceridemia. Second, a low level of HDL cholesterol is a disease marker for advanced atherosclerosis which is related to its role as a negative acute phase reactant. Third, several strands of evidence indicate that at a low level of circulating HDL may be causally related to the development of atherosclerosis. ${ }^{25}$

The troponins are a complex of 3 protein subunits, namely troponin $\mathrm{C}$, troponin $\mathrm{T}$ and troponin I, located on the thin filaments of the skeletal and cardiac muscle fibers. Troponin $\mathrm{C}$ is the calcium-binding component, troponin $\mathrm{T}$ is the tropomyosin binding component and troponin I is the inhibitory component. As the isoforms of troponin $\mathrm{C}$ is identical in the skeletal and cardiac muscle, troponin $\mathrm{C}$ is not extremely specific for myocardial injury. The isoforms of troponin $\mathrm{T}$ and troponin I differ in the skeletal and the cardiac muscle, and thus are extremely specific for cardiac tissue necrosis. Troponin $\mathrm{T}$ is present chiefly in the bound form to the contractile elements of the myocardial cells; however, it is also present free in the cytoplasm. Troponin $\mathrm{T}$ exhibits a dual release initially of the cytoplasmic component and later of the bound component. Troponin I is extremely specific for the cardiac muscle and has not been isolated from the skeletal muscle. This absolute specificity makes it an ideal marker of myocardial injury. They are released into the circulation 6-8 $\mathrm{h}$ after myocardial injury, peak at 12-24 h and remain elevated for 7-10 days. The only disadvantage of cTn is the late clearance that makes it difficult to identify a recurrent myocardial infarction. ${ }^{4}$ We tried to find a correlation between $\mathrm{TN}-\mathrm{t}$ and serum lipid but we failed to find this correlation, on the other hand, other markers as total CK and CK-MB showed correlation with cholesterol by using Spearman correlation test.

$\mathrm{CK}$ is an enzyme that is found primarily in the cardiac muscle and skeletal muscle. This enzyme has 3 isoenzymes: MM, MB and BB. $\mathrm{CK}-\mathrm{MM}$ is the skeletal muscle fraction, $\mathrm{CK}-\mathrm{MB}$ is the cardiac muscle fraction and CK-BB is the brain fraction of the total CK. Previously, the total CK was assessed for myocardial infarction. CK-MB is a sensitive as well as a specific marker for myocardial infarction. CKMB begins to rise 4-6 hour after myocardial infarction, peak at 24 hours and return to normal within 48-72 hours. CK-MB estimation is useful not only for diagnosis of MI but also for the diagnosis of reinfarction. ${ }^{26}$ In our study, myocardial infarction in Libyan patients may be arise as a result of some risk factors such as smoking in males, diabetes mellitus, high blood pressure, physical inactivity, and unhealthy diet in both sex.

\section{Conclusion}

This study concluded that, ages of most male patients were from 45-65 years old, but most of female ages from 55-75 years old which means that, the incidence of AMI was occurred in males earlier than females. The most prevalent risk factor in male and female patients is diabetes. Smoking is the second risk factor in males, and hypertriglyceridemia was the second risk factor among female patients. The study was also showed correlation between total CK and CK-MB and total cholesterol concentration, but this was not found between LDH, TN-t and cholesterol, on the other hand, LDH was correlated with HDLC.

\section{Acknowledgements}

None.

\section{Conflict of interest}

The author declares no conflict of interest.

\section{References}

1. Bęćkowski M. Acute coronary syndromes in young women-the scale of the problem and the associated risks. Kardiochir Torakochirurgia Pol. 2015;12(2):134-138.

2. Ugwu CE, Nwankwo SE, Meludu SC, et al. Assessment of the risk of myocardial infarction among undergraduate students in a Nigerian tertiary institution. International Journal of Healthcare and Medical Sciences. 2016;2(11):60-65.

3. Domma AM, Gamal MAB. Association between acute myocardial infarction, lipid profile and smoking habit. IOSR Journal of Dental and Medical Sciences. 2015;14(6):47-51.

4. Mythili S, Malathi N. Diagnostic markers of acute myocardial infarction. Biomed Rep. 2015;3(6):743-748

5. Lee TH, Goldman L, Lim W, et al. Serum enzyme assays in the diagnosis of acute myocardial, Elevated cardiac troponin measurements in critically ill patients. Arch Inter Med. 2006;166:2446-2454.

6. Bodor GS. Biochemical markers of myocardial damage. EJIFCC 2016;27(2):95-111. 
7. Al-Hadi HA, Fox KA. Cardiac markers in the early diagnosis and management of patients with acute coronary syndrome. Sultan Qaboos Univ Med J. 2009;9(3):231-246.

8. Smith SC, Allen J, Blair SN, et al. AHA/ACC guidelines for secondary prevention for patients with coronary and other atherosclerotic vascular disease: 2006 update endorsed by the National heart, lung, and blood institute. Circulation. 2006;113(19):2363-2372.

9. Rafaqat M, Shazma B, Muhammad Nazar A. Acute myocardial infarction; frequency of modifiable risk factors. Professional Med J. 2016;23(3):293-297

10. Lakić Biljana, Račić Maja. Frequency of risk factors in patients with acute myocardial infarction. Scripta Medica. 2016;47(2):131-139.

11. El-Menyar A, Zubaid M, Shehab A, et al. Prevalence and impact of cardiovascular risk factors among patients presenting with acute coronary syndrome in the middle east. Clin Cardiol. 2011;34(1):51-58.

12. Lanas F, Avezum A, Bautista LE, et al. Risk factors for acute myocardial infarction. The INTERHEART, Latin American Study. Circulation. 2007;115(9):1067-1074.

13. Abbas S, Riaz A, Malik N. Risk factors for coronary artery disease. Pak Armed Forces Med J. 2003;53(1):12-19.

14. Ahmed I, Shafique Q. Myocardial Infarction under 40: Risk factors and coronary angiographic findings. An King Edward Med Coll. 2003;9(4):262-265.

15. Boden WE, O'rourke RA, Teo KK, et al. The evolving pattern of coronary artery disease in the US and Canada: Baseline characteristics of the clinical outcomes utilizing revascularization and aggressive drug evaluation (COURAGE) trial. Am J Cardiol. 2007;99(2):208-212.

16. Patil SS, Joshi R, Gupta G, et al. Risk factors for acute myocardial infarction in a rural population of central India: a hospital based case control study. Natl Med J India. 2004;17(4):189-194.
17. Ribeiro DGL, De Andrade PJN, Paes Júnior JN, et al. Acute myocardial infarction: predictors of mortality at a public hospital in the city of Fortaleza, Ceara state. Arq Bras Cardiol. 2003;80(6):614-620

18. Abduelkarem AR, El Shareif HJ, Sharif SI. Evaluation of risk factors in acute myocardial infarction patients admitted to the coronary care unit, Tripoli medical centre, Libya. EMRO Journal Articles (EMHJ). 2012;18(4):332-336.

19. Jafary MH, Abdus Samad, Mohammad Ishaq, et al. Profile of acute myocardial infarction in Pakistan. Pak J Med Sci. 2007;23(4):485-489.

20. Noeman A, Ahmad N, Azhar M. Coronary artery disease in young: Faulty life style or Here do familial or both. Annals. 2007;13(2):162-164.

21. Redfors $\mathrm{B}$, Angerås $\mathrm{O}$, Råmunddal $\mathrm{T}$, et al. Trends in gender differences in cardiac care and outcome after acute myocardial infarction in western Sweden: a report from the swedish web system for enhancement of evidence-based care in heart disease evaluated according to recommended therapies (SWEDEHEART). J Am Heart Assoc. 2015;4(7):e001995.

22. Nordestgaard BG, Varbo A. Triglycerides and cardiovascular disease. Lancet. 2014;384(9943):626-635.

23. Han SH, Nicholls SJ, Sakuma I, et al. Hypertriglyceridemia and cardiovascular diseases: revisited. Korean Circ J. 2016;46(2):135-144.

24. Goswami K, Bandyopadhyay A. Lipid profile in middle class Bengali population of Kolkata. Indian J Clin Biochem. 2003;18(2):127-130.

25. Rosenson RS. Myocardial injury: the acute phase response and lipoprotein metabolism. J J Am Coll Cardiol. 1933;22(3):933-940.

26. Singh TP, Nigam AK, Gupta AK, et al. Cardiac biomarkers: When to test?-Physician perspective. JIACM. 2011;12(2):117-121. 